\title{
Introduction to OLJ Volume 25, Issue 2
}

\author{
Peter Shea \\ Editor-in-Chief, Online Learning \\ University at Albany, State University of New York
}

Interest in online education continues to grow and OLJ has received a very high volume of submissions this year. This second issue of 2021 reflects this expansion and contains 16 papers on a broad range of topics in the field of online and digital learning. The papers are organized into sections on faculty development, empirical studies, blended learning, Massive Open Online Courses (MOOC) research, k-12 education, and student issues.

The first two papers are on the topic of faculty development. The first of these is "Faculty Perceptions on Accessibility in Online Learning: Knowledge, Practice and Professional Development" by Thelma Guilbaud, Florence Martin, and Xiaoxia Newton of the University of North Carolina, Charlotte. The number of students with disabilities engaging with post-secondary education via online options has been steadily rising in recent years. This trend raises significant issues with regard to faculty readiness to serve this population through online education. The authors of this paper surveyed 182 faculty from three universities on perceptions of preparedness to design and teach accessible online courses using a battery of items related to disability laws, quality standards, utilization of tools and professional development support. The results reveal an inconsistent level of readiness. In light of these results the authors recommended that higher education institutions adjust their method of supporting online faculty and cultivate an inclusive strategy to serve all learners, including those with disabilities, to fully participate in online learning.

The next paper in this section is "Professional Development and ICT: English Language Teachers' Voices" by Lucas Kohnke of The Hong Kong Polytechnic University. There are more than a billion students learning English around the world, thus English language teachers play a critical role in $21^{\text {st }}$ century global education. Preparation of these educators needs to take into account the integration of contemporary digital tools in teaching and learning. The author of this paper seek to understand English teachers' attitudes and beliefs about different modalities of teacher preparation in ICT skills to augment their instruction. Results indicate that these English instructors preferred more informal methods of professional development, and that they believed that sharing good teaching approaches was the most useful practice in developing ICT skills for improving their teaching.

The next section of this issue contains four empirical studies on various topics. The first of these is "Moderating Relationships: Non-Designer Instructors' Teaching Presence and Distance Learners' Cognitive Presence" by Laura Silva of Los Angeles Pacific University, Mary Shuttlesworth of La Roche University, and Phil Ice of Analytikus. As online learning has grown so has the number of part-time faculty teaching online courses. Frequently such faculty do not develop the course that they are assigned to teach, but rather "inherit" a previously developed 
course from either another member of the faculty or even from a course design team. Framed within the Community of Inquiry model, this presents a challenge. Previous research on the COI framework indicates that students recognize and appreciate good course design elements and that course design predicts numerous student outcomes including course satisfaction as well as perceptions about proxies for higher order learning processes such as "cognitive presence". This paper looks at the more constrained teaching presence that non-designing instructors (NDIs) exhibit and its prediction of student reports of cognitive presence. The authors find that though the NDIs do not engage in designing the course, remaining measures of teaching presence, such as facilitation of discourse, do predict student ratings of cognitive presence.

The fourth paper in this issue, also grounded in the Community of Inquiry framework, is "The Community of Inquiry in Writing Studies Survey: Interpreting Social Presence in Disciplinary Contexts" by Mary Stewart of California State University San Marcos, Lyra Hilliard of the University of Maryland, Natalie Stillman-Webb of the University of Utah, and Jennifer Cunningham of Kent State University. Disciplines are defined in part by the language participants use, the practices in which they routinely engage, and the nature of the knowledge they seek to preserve and advance. Instructional practices that work well in one discipline may not be well received or effective in another. Therefore it is important to examine disciplinary difference when we attempt to measure online pedagogical environments using tools such as the COI survey. Online instructional practices that work in one content area may not work equally well in another. The authors of this paper apply the COI framework to a specific disciplinary content area, first year writing, to attempt to surface nuanced differences in how students respond to the application and measurement of the COI in this disciplinary context. This study provides a detailed investigation of the items in the COI survey and tries to determine if student ratings of each of the forms of presence demonstrate that they are actually participating in the kinds of collaborative learning that is valued by the discipline. The possibility exists that students rate various dimensions of presence positively and are still not engaged in joint knowledge construction or, conversely, that they rate the items negatively and do believe that they are engaged in a community of inquiry anyway. The authors conclude that generally, the learners are satisfied in the online and blended courses, are working together with fellow students and the instructor, and report they are achieving some transferable abilities. However the authors conclude that these results do not, per se, indicate that the courses are operating as communities of inquiry as Writing Studies aspires, where students negotiate meaning with each other and in due course actually co-construct knowledge. One indicator of this is that students were less likely to value student-student interaction than content interaction. More research is needed to understand disciplinary differences in online educational settings relative to the $\mathrm{COI}$ framework.

Continuing with papers informed by the Community of Inquiry framework within a specific discipline (Business) is the fifth paper in this issue, "Learner Presence Matters: A LearnerCentered Exploration into the Community of Inquiry Framework" by Catherine Honig and Diane Salmon of National Louis University. Building on work that my colleagues and I initiated, the authors note that "learner presence" has materialized as a prospective fourth construct to the original CoI framework. They examine this potential addition to the model by prompting learners' observations, thoughts, and actions on their participation in MBA online and blended courses. The papers uses both survey and in-depth interview methodologies. Results demonstrate how learners experience a community of inquiry and provide insights into the nature of $\mathrm{CoI}$ in one unique learning context. The authors conclude that learner presence, defined by a multi-dimensional model of learner agency, lies at the center of the Community of Inquiry framework. 
The sixth paper in this issue is "Powerful or Powerless? Chief Online Education Officers' Legitimate Power over Online Program Quality in U.S. Higher Education Institutions" by Georgianna Laws of Maryville University. With the growth and increased competition between online programs, these online offerings have taken on an increased importance as sources of revenue at institutions of higher education. With this increased profile additional roles have developed, including the relatively new role chief online education officer (COEO). COEOs are nominally responsible for the ultimate quality of online programs but it is unclear what authority they wield in taking on this responsibility. The research on this population is still very limited and this study sought to describe the relationship between COEOs' legitimate power (referencing a sixfactor model of that construct) and their ability to influence program quality. Results of the study identify a positive relationship between overall legitimate power and program quality as measured by the OLC Quality Scorecard, a frequently employed metric of online program quality. The author suggests that, given overall power seems to have a strong positive correlation with overall quality, it might be advisable for leaders to consider fashioning their COEO's job description so that power levels are proportionate with the desired quality levels for which the hired COEO will be responsible. More details are included in the paper's discussion section.

The next paper is "Taking Away Excuses to Quit: The Role of Structural Supports in Completion and Learning within Online Professional Development" by Sara Rutherford-Quach of SRI International, Karen Thompson of Oregon State University, Claudia Rodriguez-Mojica of Santa Clara University, and Diego Román of University of Wisconsin at Madison. The authors note that for under-resourced districts, schools and teachers, free professional development may be the only option. The authors of this study investigate the efficacy of providing in person structural supports to English language educators undergoing professional development in a free Massive Open Online Course (MOOC) to determine if there are benefits to augmenting free online courses through a blended approach. The paper focuses on two research questions investigating the relationship between structural supports provided by districts and teachers' completion of the online professional development and the relationship between structural supports and evidence of teacher learning within the course. The authors conclude that the structural supports do address some of the common problem of dropout with teachers receiving these supports completing the MOOC at higher rates. The issue of enhanced learning is less clear, and the paper provides a discussion of issues related to measuring learning amongst this population.

The next paper is set in a k-12 context and titled "Motivations among Special Education Students and their Parents for Switching to an Online School: Survey Responses and Emergent Themes" by DeLaina Tonks, Mountain Heights Academy, and Royce Kimmons and Stacie Mason of Brigham Young University. Increasing numbers of students in special education are enrolling in online school programs while research into this population lags. This paper seeks to investigate this trend by asking why families of students with specific special education needs choose an online option. The authors also investigate additional contextual factors. Results reveal that the three most common reasons for selecting an online option were flexibility, previous poor fit, and teacher availability. Additional analyses indicate that students had left brick and mortar schools where they had experienced bullying, struggled academically, lacked adequate support, and did not receive legally mandated accommodations. This research adds to a relatively impoverished literature on k-12 virtual schooling for special needs students.

The eighth study in this issue also covers students with special needs. The paper is "Functionality, Impact, and Satisfaction of a Web-based and Mobile Application Support Program 
for Students with Autism Spectrum Disorder" by Monica Bellon-Harn and Vinaya Manachaiah of Lamar University. Many students with Autism Spectrum Disorder do not enroll in higher education, though capable of succeeding in college. The authors of this paper note the potential to provide online support to such students through web-based and mobile applications. The goal of this study was to assess a web and mobile based support app designed to address the needs of students with Autism Spectrum Disorder. Explicit purposes were to evaluate the functionality, content, presentation, suitability, usability and exercise materials with a panel of experts and to and to assess the impact of the program with future or newly enrolled students with autism. Results suggest strengths and weaknesses of the program and future directions for research and development.

The next paper is "Realistic Job Preview as an Alternative Tool to Improve Student Readiness for Online Learning" by Zahir Ibrahim Latheef and Robert Robinson of the University of Houston and Sedef Smith of the Branch Alliance for Educator Diversity. The issue of student preparedness for online learning is conventionally managed through online learning readiness assessments that present students with statements or questions that evaluate their understanding of the knowledge, skills, abilities and attitudes needed to be successful in an online environment. The authors of this paper propose that another widely researched tool can be used for preparing people for new educational roles - Realistic Job Preview (RJP). The purpose of RJP is to set realistic expectations for recruits or new employee about an organization and the job in question. More accurate expectations have a favorable effect on performance, attitudes, retention. These authors adapt RJP for the purpose of an online learning readiness assessment by developing a video of a realistic preview of online learning. The video included segments by students who had previously participated in online courses and explains what to expect from these learning environments. Results support including or adding RJP as a strategy to improve student readiness for online.

The tenth paper is "Examining Students' Online Course Perceptions and Comparing Student Performance Outcomes in Online and Face-to-Face Classrooms" by Dan Spencer and Traci Temple of the North Carolina State University. This study examined online courses using existing grade and student survey data and explored possible differences in success rates between online and face-to-face courses for full-time students. The paper also investigates student perceptions of online education at the university in which the study was conducted. Using regression techniques on a sample of 270,939 cases over a five year span the authors found that students were slightly less likely to obtain a passing grade in online courses compared to face-toface courses and reports interactions between student demographics and success in the two instructional settings. This paper also presents survey data indicating students reported a preference for face-to-face formats though experiences online were largely positive. This paper, based on a large sample and rigorous methods, contributes to a broader literature on online student success with frequently conflicting results. Past results have found similar, small course grade decrements but have also found higher rates of graduation among students who take online coursework.

Next is "Investigating E-Learning Motivational Strategies of Higher Education Learners against Online Distractors" by Ali Erarslan and Meral Şeker of Alanya Alaaddin Keykubat University, Turkey. These authors note that establishing and maintaining academic engagement can be challenging, especially in online learning environment where learners are exposed to near constant distraction. This study investigates online distractors and strategies to overcome these challenges. Using survey and interview methods the authors find that preparing learners with 
motivational e-learning strategies integrating goal commitment and volition factors is a promising approach.

The next paper in this issue is "Designing Educational Videos for University Websites Based on Students' Preferences" by Zainab Alfayez of the University of Basrah, Iraq. The study explored learner experience with educational videos commonly found on the social media site YouTube. Noting the proliferation of video for educational purposes the authors of this paper explored numerous questions through qualitative interview research. These included students' interest in using video hosted by their universities, beliefs about how video might help in their studies, preferences of visual design, and developing video design based on student preferences. Results indicate that many of the interviewees question the accuracy of video content on social media. The authors present additional results and recommendations about hosting and design of educational video to reflect student concerns and preferences.

The next paper in this issue is "Exploring the Impact of an Open Access Mindfulness Course with Online Graduate Students: A Mixed Methods Explanatory Sequential Study" by Jackie Lyn Murphy of Drexel University. Stress-induced distraction experienced by many online students can have a negative impact on learning including decreased reading comprehension, divided attention in lectures, and lowered academic performance overall. Mindfulness based meditation has a well-documented history of reducing stress and increasing concentration. Graduate students in online program typically juggle multiple roles so encounter high levels of stress and frequent distraction from jobs, families and other commitments. The authors of this study developed an online mindfulness training module to help graduate students in online programs learn to use mindfulness practices to ameliorate feelings of stress and distraction. They found that self-reported levels of stress and mind wandering were significantly lower after students finished the module. The application of mindfulness techniques to education is becoming more prevalent and this study suggests paths for future research.

The final paper in the June issue is "Piloting Learning Analytics in a Multidisciplinary Online Program" by Rob Nyland, Benjamin Croft, Eulho Jung of Boise State University. Learning analytics have been with us for more than a decade and their promise of improving student success outcomes has not yet been fulfilled. The authors of this paper seek to answer three questions that might allow for achieving this goal in the online program context. First they seek to understand how faculty and advisors feel about the helpfulness of the reports developed by learning analytic systems. Faculty and advisors play a crucial role in the benefits that may accrue with analytics. Without consideration of their needs learning analytics will not succeed. The second question asks which interventions are most commonly triggered by the learning analytics systems. Understanding the most common interventions can allow for further integration and other benefits. Finally, the authors seek evidence of impact in online program outcomes. The paper provides various insights on these questions and thus may help advance research and practice of learning analytics.

In closing, I would thank our editors, reviewers, and editorial staff for their ongoing contributions to the journal and to the field of online learning. We invite you to read and share this issue with colleagues and to consider submitting your original work to Online Learning. 